\title{
A GESTÃO DA QUALIDADE COMO ESTRATÉGIA DE SUPORTE PARA O DESENVOLVIMENTO DE COLEÇOES EM BIBLIOTECAS JURÍDICAS
}

\author{
QUALITY MANAGEMENT AS A STRATEGY TO SUPPORT COLLECTION DEVELOPMENT \\ IN LEGAL LIBRARIES
LA GESTIÓN DE LA CALIDAD CÓMO ESTRATEGIA DE SOPORTE PARA EL DESARROLLO DE COLECCIONES EN BIBLIOTECAS JURÍDICAS

Ana Cláudia Carvalho de Miranda ${ }^{1}$,
Mônica Marques Carvalho Gallotti ${ }^{2}$,
Erlano Silva de Miranda ${ }^{3}$

\section{RESUMO}

As bibliotecas são entendidas como organizações sem fins de lucro, cujo objetivo principal é propor serviços de qualidade em torno da mediação da informação com vistas ao atendimento de necessidades de informação específicas de determinados grupos de usuários. Nesse sentido, como organizações, necessitam ter estratégias de gestão específicas que garantam sua eficácia e eficiência para garantir a sua sobrevivência. Dentre algumas estratégias temos da gestão pela qualidade. Este artigo se propõe debater a questão da gestão da qualidade por meio do estudo do processo de Desenvolvimento de Coleções de Bibliotecas Jurídicas. Para o embasamento e consecução dos objetivos propostos foi feita uma revisão de literatura que considera as áreas da Qualidade, do Desenvolvimento de Coleções, buscando-se identificar suas principais características enquadrando-se o universo específico das Bibliotecas Jurídicas. Neste contexto, são caracterizados elementos relacionados ao assunto tais como Bibliotecas Jurídicas, Informação jurídica, e apontados os principais desafios enfrentados na gestão de coleções jurídicas bem como possíveis soluções. Com base nas reflexões propostas, pode-se confirmar que o papel da biblioteca jurídica é difundir a informação jurídica nas instituições das quais fazem parte, apoiar as decisões nos processos judiciais em curso levando-lhes o Direito em seu estado bruto para que possa ser lapidado através das regras de interpretação, achando-se ao final a norma a ser aplicada na solução do caso, contribuindo para pacificação da sociedade. Conclui-se que para que este processo se cumpra torna-se necessário a aplicação eficaz de estratégias que garantam a qualidade dos serviços propostos.

PALAVRAS-CHAVE: Bibliotecas Jurídicas. Qualidade. Desenvolvimento de Coleções.

\section{ABSTRACT}
Libraries are seen as non-profit organizations, their main objective is to offer quality in information mediation, in order to meet the user's specific information needs. Thus, as organizations, libraries need to apply management strategies that aim to guarantee its effectiveness and efficiency to ensure its survival. Amongst some strategies is quality management. This article aims to propose a debate regarding quality management applied to Collections Development in Legal Libraries. In order to attend these objectives, literature review was realized considering the areas of Quality, Collection Development. In this process, the research identifies the main characteristics applied to Law Libraries, characterizes Legal information as well as points out the main challenges in this area and possible

\footnotetext{
${ }^{1}$ Mestra em Administração pela UFRN. Chefe da biblioteca do Tribunal de Justiça do Rio Grande do Norte. Natal, Rio Grande do Norte - Brasil. http://orcid.org/0000-0002-8049-1182. Email: anaclaudia.biblio@ gmail.com

${ }^{2}$ Doutoranda em Informação e Comunicação em Plataformas Digitais pela Universidade do Porto. Professora Assistente do Departamento de Ciência da Informação da UFRN. Natal, Rio Grande do Norte - Brasil. http:// orcid.org/0000-0002- 30442032. Email: monica_mcg@ hotmail.com

${ }^{3}$ Bacharel em Direito pela Universidade Federal do Rio Grande do Norte. Atua na Delegacia da Receita Federal do Estado do Rio Grande do Norte. Natal, Rio Grande do Norte - Brasil. http://orcid.org/0000-0002- 8732-9858. Email: erlano.23.sm@gmail.com

Enviado em: 01/03/2016 - Aceito em: 20/05/2016.

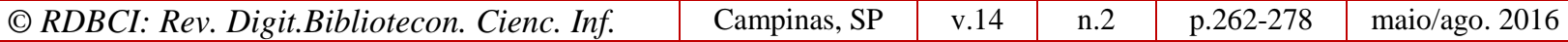


solutions. Based on the reflections given, it can be confirmed that the role of the legal library is to disseminate legal information in the institutions to which they belong to, support legal decisions, work with law in its raw state so it can be interpreted, aiming to reach certain standards contributing to peace in society. It is concluded that for this process to be fulfilled it is necessary the effective implementation of strategies for ensuring the quality of the provided services. KEYWORDS: Legal Libraries. Quality. Collection Development

RESUMEN: Las bibliotecas son comprendidas como organizaciones sin fines lucrativos, cuyo objetivo principal es proponer servicios de calidad alrededor de la mediación de la información con vistas al entendimiento de necesidades de informaciones específicas de determinados grupos de usuarios. En este sentido, como las organizaciones necesitan de estrategias de gestión específicas que aseguren su eficacia e eficiencia para garantizar su supervivencia. Entre algunas estrategias tenemos la de la gestión por la calidad. Este artículo se propone a debatir/aportar la cuestión de la calidad por medio del estudio del proceso de Desarrollo de Colecciones de Bibliotecas Jurídicas. Para El fundamento/soporte y consecución de los objetivos propuestos ha sido hecho un repaso de la literatura que considera las áreas de Calidad, del Desarrollo de Colecciones, buscándose identificar sus principales rasgos encajándose al universo específico de las Bibliotecas Jurídicas. En este contexto, son caracterizados elementos relacionados al asunto tal cómo, Bibliotecas Jurídicas, Información jurídica y señalados los principales retos enfrentados en la gestión de colecciones jurídicas así como posibles soluciones. Con base en los reflejos propuestos, se puede confirmar que el papel de la biblioteca jurídica es difundir la información jurídica en las instituciones de las cuales hace parte, apoyar las decisiones en los procesos judiciales en curso llevándoles el Directo en su estado natural a fin de que pueda ser lapidado a través de las reglas de interpretación, hallándose al final la norma a ser aplicada en la solución del caso, contribuyendo para pacificación de la sociedad. Se concluye que para que se cumpla este proceso se hace necesario la aplicación eficaz de estrategias que aseguren la calidad de los servicios propuestos.

PALABRAS CLAVE: Bibliotecas Jurídicas. Desarrollo de Colecciones. Gestión de la Calidad.

\section{INTRODUÇÃo}

As organizações no mundo atual estão em constante mutação como resposta a uma sociedade que também se altera constantemente. Nesse sentido, para sobreviver e atingir seus objetivos as organizações precisam adaptar-se a este ambiente complexo. A adaptação e sobrevivência das mesmas só é possível por meio da oferta de serviços de excelência.

As Bibliotecas são, de fato, organizações sem fins de lucro, que visam prestar serviços em torno da mediação de informação e o atendimento às necessidades informacionais dos seus usuários. Como toda organização, as bibliotecas visam adaptar-se ao ambiente multifacetado por meio de estratégias com vistas a um gerenciamento mais eficaz de seus recursos e serviços bem como atingir (continuamente) a excelência em Serviços de Informação, considerando os usuários como peça fundamental para alcançarem seus objetivos e metas. Para que continuem a prestar serviços relevantes precisam adequar-se e lançar mão de estratégias tais como a Gestão da Qualidade visando agregar valor aos serviços praticados.

O tema "qualidade em serviços", devido a sua importância, tem sido profusamente debatido e questionado entre pesquisadores, gerentes e administradores (FREITAS, 2005). De forma genérica, tal questionamento é oriundo da relação de dois objetos de entendimento não tão triviais: qualidade e serviços. De modo geral, os atores envolvidos no processo buscam detectar, dentre outros aspectos: os critérios que melhor definem a qualidade de um serviço particular e aqueles que geram mais satisfação (ou quando no caso, a insatisfação) do cliente; 
outrossim visam identificar o impacto da qualidade do serviço e satisfação do mesmo nas intenções de consumo (CRONIN \& TAYLOR, 1992). Entende-se que qualidade dos serviços varia de acordo com o contexto em que as organizações estão inseridas, seus objetivos e metas e - acima de tudo - sua natureza. No entanto, torna-se necessário promover e ampliar a reflexão sobre este tema em contextos específicos.

Diante disso, este trabalho se propõe a abordar conceitos e aspectos da Qualidade em Serviços, tratando em específico o caso das Bibliotecas Jurídicas com ênfase na informação forense. Sob este aspecto, visa analisar a questão da formação e desenvolvimento de coleções nesse tipo de biblioteca. Destacam-se entre outros elementos, as técnicas, critérios e metodologias utilizadas que, com vistas a atender as necessidades de informação dos usuários e sua consequente satisfação pela qualidade do serviço prestado. Inicialmente, será debatida a questão da Qualidade, em seguida enfatizaremos os pressupostos da qualidade aplicados ao universo da informação. Mais adiante, abordaremos o assunto específico das bibliotecas jurídicas, conceituando-se informação jurídica; detalharemos os procedimentos ligados ao Desenvolvimento de Coleções em Bibliotecas próprias do ambiente forense, apontando-se as principais características e desafios inerentes a este processo.

\section{QUALIDADE}

Como vimos, no mundo moderno, sobretudo a partir do avanço tecnológico experimentado em meados do século passado, o grande desafio das organizações é permanecerem competitivas diante de profundas e rápidas transformações econômicas, políticas, sociais e de relações de trabalho. Este panorama impõe um (re)pensar da forma como a gestão das organizações vem sendo realizada nos mais diversos setores. As organizações que se destacam e têm se mostrado duradouras no mercado são as que primam pela qualidade de seus serviços, buscam uma gestão eficaz, fazem o manejo apropriado de seus recursos e - acima de tudo - valorizam as necessidades de seu público alvo tais como os seus clientes (internos e externos).

Inserida nesse cenário, está a gestão pela qualidade. Essa área tem como objetivo básico propor estratégias com vistas a diminuir o desperdício e o retrabalho por meio de um processo educacional que conscientiza as pessoas de que a qualidade é um compromisso de todos da organização. A gestão da qualidade visa desenvolver meios e métodos para conquistar e conservar sua clientela, compreendendo que seus colaboradores, a gerência e os fornecedores são os primeiros clientes que devem ser fidelizados.

Um dos primeiros indícios em torno da preocupação com a qualidade remonta da década de 1920, propostos por W. A. Shewart, logo após a $2^{\text {a }}$ Guerra Mundial. Suas teorias contribuíram para a criação dos primeiros parâmetros aplicados aos processos de qualidade levado adiante por W. Edwards Deming, que revolucionou a economia americana e japonesa. Embora já existam muitos conceitos identificados pela literatura, expressa por parte dos principais pensadores da área da Qualidade, ainda se faz necessário maior debate sobre o assunto.

Segundo a NBR ISO 9000, gestão da qualidade é conjunto de "atividades coordenadas para dirigir e controlar uma organização no que diz respeito à qualidade" (Associação \begin{tabular}{|c|c|c|c|c|c|}
\hline (C) RDBCI: Rev. Digit.Bibliotecon. Cienc. Inf. & Campinas, SP & v.14 & n.2 & p.262-278 & maio/ago. 2016 \\
\hline
\end{tabular} 
Brasileira de Normas Técnicas, 2000, p. 8). Portanto, são essencialmente processos e ações que visem propor critérios sólidos para a melhoria da gestão com vistas a atingir os objetivos da organização. Esta definição é corroborada por Crosby (1984) quando aponta a qualidade como sendo o cumprimento de requisitos, uma atitude de acertar logo da primeira vez o padrão de desempenho desejado. No entanto, os objetivos da organização não podem ser atendidos sem a satisfação dos seus clientes e a qualidade é inerente a este processo. A este respeito Juran (1992) considera qualidade como sendo a adequação ao uso dos serviços por parte dos clientes, que é determinada pelas características do produto que o cliente julga serem benéficas a ele. Esta afirmativa por sua vez, é apontada por Deming (1990, p.124) quando coloca que a "qualidade só pode ser definida nos termos de quem avalia". Já Feigenbaum (1994) destaca que a qualidade é fundamentada na experiência real do cliente com o produto ou serviço, medida de acordo com suas exigências, sejam elas explícitas ou não, correspondendo à expectativa dos usuários que, por sua vez, gera o retorno desejado.

Pode-se ver, portanto acima, que a qualidade é um atributo subjetivo, atendido conforme a percepção de quem consome o serviço. Além de subjetiva é contingencial, dependendo da natureza dos serviços a serem oferecidos. No geral, a qualidade se reporta a um conjunto de atividades com a finalidade de enquadrar um produto ou serviço entre os requisitos que atendam às expectativas e necessidades dos clientes visando a sua satisfação.

Portanto, a qualidade total é uma meta contínua idealizada para se alcançar a o desenvolvimento das organizações no mundo moderno, mirando não somente ampliar a competitividade de seus produtos e serviços, mas também, fundamentalmente, a manter-se relevante no mercado A seguir, faremos uma breve explanação de como a gestão pela qualidade se inter-relaciona com o universo informacional.

\subsection{A questão da qualidade aplicada ao universo informacional}

Nos últimos séculos, devido a grandes avanços na tecnologia da informação a sociedade tem sido marcada pelo fluxo constante e elevado de informações. Esse fato é responsável por alterações importantes no design de serviços de informação e no atendimento a padrões de qualidade. Uma vez que há uma expressiva quantidade de novas informações e grande velocidade de conhecimento sendo absorvido e gerado, torna-se fundamental que as bibliotecas levem isso em consideração ao prestarem seus serviços. Essa nova "explosão informacional" " 4 tem levantado vários questionamentos sobre a fidedignidade do conteúdo produzido. Essa realidade tem afetado a formação de acervos em bibliotecas e exige dos bibliotecários uma atuação diferenciada em razão do descontrole provocado pela "poluição informativa". Quanto mais informação produzida, mais critérios em torno se sua "filtragem" são necessários. Torna-se fundamental obedecer a padrões de seleção e qualidade que garantam a disponibilidade de obras confiáveis nos diversos suportes informacionais.

\footnotetext{
${ }^{4}$ A primeira explosão informacional registrada na história dá-se com a invenção dos tipos móveis por Gutenberg no século XVII. Mais modernamente, sobretudo após os anos 70 do século XX, a sociedade experimenta uma nova "explosão" que ocorre com a aplicação da tecnologia da informação que tem impactado sobremaneira a captação, organização e difusão das informações.
} 
A informação para ter qualidade necessita ser relevante, confiável, atual, acessível, precisa, oportuna e deve ser ajustada às demandas e expectativas dos usuários. $\mathrm{O}$ valor da informação está associado a sua utilidade. Nesse sentido, na biblioteca, a qualidade poderá ser mensurada de acordo com o "consumo" por parte dos usuários da informação contida nos diversos tipos de suportes de informação. Para tanto, será necessário elencar estratégias que assegurem que a seleção destes suportes esteja dentro de um padrão de qualidade.

A conquista da qualidade nos produtos e serviços não é algo estático; pelo contrário, é um processo contínuo que busca melhorar e atingir a eficácia sistemática nos níveis de desempenho. O atendimento da qualidade é realizado por meio de projeções atentas, fundamentadas em dados que subsidiem o processo de tomada de decisão e atendimento dos planos e metas e acima de tudo, atendendo-se às expectativas dos envolvidos no processo.

Uma das estratégias para se garantir o atendimento de objetivos informacionais neste ambiente é o desenvolvimento de coleções. É a partir deste procedimento que é possível se estabelecer diretrizes para ações voltadas à gestão da coleção como um todo, bem como o estabelecimento de políticas que visam a um tratamento e disseminação eficaz da informação, elementos fundamentais para o sucesso das bibliotecas como organizações. Neste ínterim, a qualidade precisa estar ajustada ao universo e contexto específico em que está inserida a biblioteca. Diferentes tipos de bibliotecas exigem diferentes estratégias. Torna-se fundamental discutir casos específicos para que se debatam as melhores soluções. Nesse sentido, a seguir abordaremos o caso específico das bibliotecas jurídicas para, em seguida, abordar como se dá o desenvolvimento de coleções neste ambiente específico.

\section{AS BIBLIOTECAS JURÍDICAS E O UNIVERSO DA INFORMAÇÃO JURÍDICA}

Pode-se dizer que a informação tornou-se a mais poderosa força de transformação do homem, presente por meio de suas relações sociais, econômicas e culturais, sendo um elemento decisivo para o alcance da cidadania. A informação, quando usada sabiamente, contribui como instrumento formador da consciência crítica do indivíduo, podendo levá-lo à conquista do sucesso intelectual e profissional, caso contrário, pode levá-lo ao fracasso e à própria estagnação.

Para Capurro e Hjorland (2007), o conceito de informação é algo inerente ao homem, percebido de acordo com a sua subjetividade e acima de tudo, relativo ao seu contexto social. Para o autor, isso ocorre uma vez que os homens se organizam de acordo com determinadas situações sociais e que cada uma dessas situações (subjetivas por natureza) acontece com intenções específicas e relativas a determinados grupos, daí a dificuldade de se precisar o que seria informação. Sua definição não pode se dar isoladamente. Como a informação tem sido valorizada são muitos os conceitos que surgem e o tema vem sendo debatido profusamente ${ }^{5}$. Neste sentido, são vários os tipos de informação e, dentre estes, a informação jurídica.

\footnotetext{
5 São variados os autores que de dedicam a conceituar a Informação, dentre alguns destacamos: Le Coadic (1996, p.5) que a define como sendo "um conhecimento inscrito (gravado) sob a forma escrita (impressa ou numérica), oral ou audiovisual". Já Silva \& Ribeiro (2002) apontam que a informação: "Refere-se a um fenômeno humano e social que compreende tanto o dar forma a ideias e a emoções (informar), como a troca, a efetiva interação dessas ideias e emoções entre seres humanos (comunicar), identifica um objeto científico, que vem a

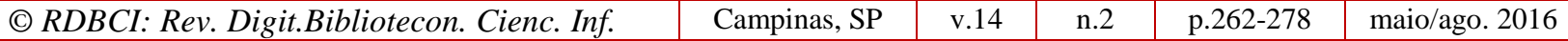


A informação jurídica é o recurso principal e matéria prima das bibliotecas jurídicas. Esse tipo de biblioteca pode ser entendido como sendo uma unidade de informação especializada por natureza que visa, dentre outras funções a de promover a mediação da informação jurídica. Para isso emprega meios de localização, acesso, organização, representação e difusão deste tipo de informação. Todos os seus serviços são voltados para o atendimento das necessidades de informação específicas de seu público. Para Alonso (1998 apud REZENDE 2004, p. 175), A informação jurídica é definida:

[...] sob o aspecto genérico, pode ser conceituada como qualquer dado ou fato, extraído de toda e qualquer forma de conhecimento da área jurídica, obtido por todo e qualquer meio disponibilizado e que pode ser usado, transferido ou comunicado sem a preocupação de estar integrado a um contexto. É um dado ou qualquer elemento identificado em sua forma bruta que, por si só, não conduz a uma compreensão de determinado fato ou situação.

Portanto, este tipo de informação provém de uma documentação específica organizada presente na esfera jurídica. Para a sua difusão, precisam estar registradas, classificadas, organizadas, interpretadas para se permitir a tomada de decisão por parte do usuário jurídico de forma mais sistemática e organizada. Sua maior função é contribuir não apenas para o exercício da cidadania, mas, também, como prerrogativa de garantia dos direitos individuais, pois todo cidadão necessita estar a par dos seus direitos.

De acordo com Passos (1994, p.363), esse tipo de informação é definido como:

Toda unidade de conhecimento humano que tem a finalidade de embasar manifestações de pensamento de jurisconsultos, advogados, legisladores, desembargadores, juízes e todos aqueles que lidam com a matéria jurídica, quando procuram estudar (do ponto de vista legal) ou regulamentar situações, relações e comportamentos humanos, ou ainda quando interpretam e aplicam dispositivos legais.

A informação jurídica é originada fundamentalmente por um tripé informacional, distinto: Legislação, Doutrina e Jurisprudência. Legislação é o conjunto normativo que regula a convivência social. A Doutrina é o conjunto de princípios expostos nas obras de direito, em que se firmam teorias ou se fazem interpretações sobre a ciência jurídica. E a jurisprudência é a sábia interpretação e aplicação das leis a todos os casos concretos que se submetem a julgamento da justiça, que produz sentenças no primeiro grau, ou acórdãos e súmulas nos Tribunais (MIRANDA, 2004). Já Machado (2000) chama atenção no tocante à Legislação e à Jurisprudência. Sua recuperação inadequada ou incompleta gera insatisfação aos seus usuários, como pode causar danos, especialmente aos juristas, englobando todos aqueles que se utilizam dela e as partes. Apesar de a doutrina não exigir uma recuperação exaustiva, há necessidade de atualização constante.

O volume de informação jurídica gerada e demandada tem aumentado exponencialmente, em decorrência da constante atualização da legislação, alterando todo o sistema do Direito. Conforme ressaltam Passos e Barros (2009), as atualizações constantes da

ser um conjunto estruturado de representações mentais e emocionais codificadas (signos e símbolos) e modeladas com //pela interação social, passíveis de serem registradas num qualquer suporte material (papel, filme, banda magnética, disco compacto etc.) e, portanto, comunicadas de forma assíncrona e multidirecionada". 
legislação tornam a informação jurídica normativa um grande caos informacional, dificultam o trabalho de advogados, pesquisadores e a vida do próprio cidadão, levando à morosidade da justiça, situação em que nem mesmo um especialista consegue hoje conhecer todas as normas de seu campo de atuação. Esse fato impõe por sua vez desafios pontuais para a gestão e difusão deste tipo de informação.

Diante desse cenário, Barros (2004) destaca a "explosão" de informações jurídicas devido a grande quantidade de documentos expedidos pelas autoridades legislativas, judiciárias e administrativas, como, também, da complexidade das especificações da área.

A informação jurídica é elemento imprescindível para que se alcancem objetivos no âmbito jurídico, havendo, portanto, uma necessidade de sistematização destes dados para que haja um controle e um alcance destas propostas. Em se tratando de organização dos dados e informações jurídicas, a bibliotecas inseridas neste contexto assumem uma importante função: o de aglutinar a informação que servirá de base para a promoção e suporte de serviços forenses.

Neste sentido, as bibliotecas jurídicas objetivam disseminar a informação jurídica, especialmente na esfera de suas instituições mantenedoras, com o intuito de subsidiar as decisões processuais em fluxo, como também auxiliando a todos os juristas no cumprimento da justiça. Este tipo de biblioteca está presente sobretudo em ambientes tais como: órgãos governamentais, fóruns, universidades ou escritórios de advocacia, dentre outros.

Passos (2002, p.1) destaca que "os usuários típicos dos serviços de uma biblioteca jurídica são juízes, juristas, legisladores, professores e alunos do curso de Direito e o cidadão comum" que têm como objeto de pesquisa: leis, doutrinas, jurisprudências e julgados dos mais diversos Tribunais. A demanda da informação jurídica tem aumentado em consequência do público interessado em prestar concursos públicos, não apenas e - especificamente - aos destinados à carreira jurídica, mas para outras que no programa abrangem também algumas áreas jurídicas. As bibliotecas jurídicas devem estar organizadas visando à satisfação de necessidades informacionais específicas desse público. Nestes termos, elas planejar adequadamente o desenvolvimento de suas coleções, com a finalidade de terem seus acervos sempre atualizados e relevantes para satisfazer seu público alvo. Em seguida, apontaremos como se dá o Desenvolvimento de Coleções e abordaremos como se realiza essa questão no universo específico das bibliotecas jurídicas.

\section{DESENVOLVIMENTO DE COLEÇões}

Como vimos anteriormente, variados fatores concorrem para que haja a necessidade inconteste de aprimoramento dos serviços prestados em bibliotecas, fazendo com que as elas lancem mão de estratégias administrativas específicas para a garantia de melhor provisão de serviços. Dentre eles podemos apontar o Desenvolvimento de Coleções. Desenvolver coleções implica sistematizar, criar procedimentos para seleção, aquisição, avaliação e desbastamento do acervo. As coleções precisam evoluir harmoniosamente em todas as áreas científicas, evitando um crescimento desordenado, sem metas ou objetivos definidos. A esse respeito, Figueiredo (1999) aponta que a coleção precisa ser equilibrada e atender as 
necessidades do público consumidor de informação, sintonizado com os objetivos de cada tipo de biblioteca. Ao se iniciar o processo de desenvolvimento de coleções, devemos primeiramente realizar um estudo da comunidade com o intuito de estabelecer os perfis das necessidades informacionais. Depois de concluído o diagnóstico, serão tomadas algumas decisões quanto às políticas que conduzirão o processo de desenvolvimento de coleções. Dentre as quais, Maciel (2000) destaca as seguintes:

- indicação do responsável pelo processo de seleção que poderá ser o bibliotecário ou uma comissão constituída pelo bibliotecário e outros membros nomeados pelo dirigente da instituição mantenedora;

- determinação das áreas que farão parte do acervo;

- indicação do tipo de material que irá compor o acervo, independente do seu suporte físico;

- estabelecimento dos critérios e prioridades que orientarão todo o processo, incluindo as decisões nas etapas de seleção, aquisição e também o desbastamento da coleção, indicando o que deve ser transferido para depósitos especiais ou mesmo ser descartado;

- estabelecimento de diretrizes para a avaliação das coleções, até mesmo com indicação da periodicidade com que deverá ser realizada;

- definição da quantidade de exemplares por título, especialmente para as coleções de uso correntes;

- estabelecimento de diretrizes para a preservação e conservação do acervo, contendo informações sobre as condições ambientais ideais para cada tipo de documento;

- determinação de prazos para revisão das políticas.

Concluída a elaboração das políticas, obteremos um documento administrativo oficializado perante os dirigentes da instituição designado "Política de Desenvolvimento de coleções" que deverá ser revisado a cada 02 (dois) anos pela Comissão de Biblioteca com a finalidade de garantir a sua adequação à comunidade e aos objetivos da instituição. Para efetivação do processo como um todo, faz-se mister a elaboração e adoção de parâmetros por meio da criação de critérios sólidos para apoiar os processos do desenvolvimento de coleções. Assim, a política de desenvolvimento de coleções é um documento que estabelece critérios para garantir a qualidade e a credibilidade da coleção, no tocante à tomada de decisões relacionadas com a incorporação ou a retirada definitiva de materiais pertencentes ao acervo.

\subsection{Política de desenvolvimento de coleções}

A Política de Desenvolvimento de Coleções de uma biblioteca é um documento que estabelece normas e diretrizes para auxiliar a decisão de incorporação ou rejeição de um determinado item à formação do acervo. Neste documento são registrados os critérios para seleção de todos os tipos de materiais, suas formas de aquisição bem como orientar açoes de descarte ou remanejamento. Todas as ações são direcionadas ao atendimento das necessidades de informação de seu público, facilitando - sobremaneira - o acesso, a recuperação e a disseminação do conteúdo.

Segundo Vergueiro (1989), a política de desenvolvimento de coleções funciona como um parâmetro que auxilia na tomada de decisão por parte dos bibliotecários. Visa propor

\begin{tabular}{|c|c|c|c|c|c|}
\hline (C) RDBCI: Rev. Digit.Bibliotecon. Cienc. Inf. & Campinas, SP & v.14 & n.2 & p. $262-278$ & maio/ago. 2016 \\
\hline
\end{tabular}


balizas em relação à escolha do material a ser incorporado ao acervo e subsidiar a administração dos recursos informacionais. Fornece subsídios para os bibliotecários argumentarem com as autoridades superiores tanto para a liberação de novas aquisições como para recusas incoerentes.

Para elaboração da política, Vergueiro (1989) ressalta que é imprescindível ter alguns dados essenciais à apreciação, tais como: o estado atual da coleção (quais áreas jurídicas encontram-se inadequadas, necessitando de novas aquisições e quais áreas encontram-se eficientes para atender a demanda) e as necessidades informacionais da comunidade a ser servida. Na preparação da política, é necessário que sejam estabelecidos os objetivos para darem um maior direcionamento ao acervo, visando:

- possibilitar um crescimento racional e equilibrado do acervo na área jurídica de forma qualitativa e quantitativa;

- identificar os elementos adequados à formação da coleção;

- determinar os critérios para duplicação de títulos;

- estabelecer as prioridades de aquisição de material;

- conhecer as necessidades dos usuários, por meio da análise de uso das coleções e sua atualidade;

- acompanhar o surgimento dos novos suportes de informação, não se limitando apenas ao suporte em papel, e,

- elaborar diretrizes para o descarte e reposição de material.

Uma das etapas mais importantes da política de desenvolvimento de coleções é o processo de seleção, pois por meio dele são estabelecidos os critérios que garantem a qualidade e o ajustamento para atender, a contento, as reais necessidades dos usuários.

\subsection{Processo de seleção do acervo}

O processo de seleção da informação jurídica merece destaque, pois favorece o desenvolvimento de medidas estratégicas, com a finalidade de propor critérios que busquem facilitar a tomada de decisões na formação do acervo, em parceria com os objetivos da instituição na qual a biblioteca encontra-se inserida. Para Miranda (2004), este processo torna-se cada vez mais criterioso, por diversos fatores:

- aceleração das mudanças nas leis, emendas constitucionais, decretos etc. (acarretando uma crescente obsolescência das publicações);

- intensificação da interdisciplinaridade (acoplando áreas antes isoladas);

- variedade no formato (relatórios, artigos de periódicos, anais de congressos, livros e outros) e no suporte (papel, meio eletrônico e outros).

Para a biblioteca acompanhar essa evolução, faz-se necessária uma contínua gestão da literatura jurídica, veículo do Direito, pois esta a todo instante atualiza-se frente às novas realidades sociais detectadas pela ciência do dever ser. Para tanto, é necessário averiguar-se sobre uma possível mudança significativa na área jurídica, objeto da compra, pois se corre o risco de adquirirmos documentos com valor puramente histórico, sem nenhum valor prático imediato, a princípio. Essa análise reporta a afirmação de Campos (2002) referente à $5^{\mathrm{a}}$ Lei de Ranganathan "A biblioteca é uma organização em crescimento", concomitantemente a isso 
vê-se que a produção do conhecimento é uma ação permanente. Este processo não é fácil de realizar, todavia, entre os milhões de documentos informacionais que são lançados no mercado editorial é importante registrar quais são os mais adequados para a clientela específica.

Segundo Figueiredo (1991), este processo quando bem executado irá garantir que a qualidade e o tamanho da coleção estejam em concordância com as necessidades informacionais dos usuários. Já Muller (2000, p. 24) ressalta ainda que "a política de seleção do acervo deve ser muito bem planejada e suplementada por esquemas de cooperação com outras bibliotecas". Temos como exemplo a implementação de grupos de informação jurídica já existente em vários estados brasileiros. Nestes grupos as bibliotecas jurídicas articulam-se em rede, compartilham recursos, fazem permuta bibliográfica, cooperam entre si como forma de superar possíveis limitações em suas coleções.

No entanto, a seleção da informação jurídica deve ser feita analisando-se as necessidades da instituição mantenedora e o usuário individual inserido em uma cultura organizacional, com necessidades diversificadas e demandas a serem supridas. Nesta etapa é importante levar em consideração as sugestões da comunidade de usuários. Esse procedimento é indispensável, visto que de nada valeria ter um acervo imenso, porém inadequado aos nossos clientes, pois, sem eles, a biblioteca não passaria de um depósito de documentos e deixaria de realizar seu papel de organizar, processar e disseminar as informações, objetivando sua difusão e criando meios para a proliferação do saber para futuras gerações.

\subsubsection{Critérios para seleção}

Para garantir a qualidade na aquisição de novos materiais, é necessário que sejam estabelecidos critérios para seleção. Estes, por sua vez devem tomar por base dois fatores decisivos: o interesse da comunidade a ser servida e os recursos financeiros destinados para a aquisição. A determinação dos critérios assegura que o acervo é produto de um planejamento voltado para as diretrizes e os objetivos da instituição. Alguns critérios de seleção para o desenvolvimento do acervo são: adequação do material aos objetivos da Instituição; autoridade do autor e/ou editor; atualidade; qualidade técnica; escassez de material sobre o assunto na coleção; aparecimento do título em bibliografias e índices; cobertura/tratamento; custo justificado; idioma acessível; relevância/interesse; número de usuários potenciais que poderão utilizar o material; precisão; condições físicas do material. Por serem gerais, estes critérios e nem sempre são adotados em todos os documentos, sendo necessário um ajuste para cada biblioteca, conforme a sua realidade e seus objetivos. Uma das etapas subsequentes é a do processo de aquisição.

\subsection{Processo de aquisição}

O processo de aquisição é a execução das decisões tomadas no processo de seleção, ou seja, é o procedimento destinado à obtenção dos documentos. A aquisição pode ocorrer a partir de três modalidades: a compra, a doação e a permuta. A concretização desse processo

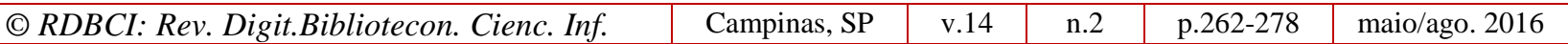


por compra requer um trabalho minucioso da parte do profissional bibliotecário visando para adequar o material às necessidades da comunidade envolvida. Já os processos de doação e à permuta, também muito importantes, exigem atenção do profissional quanto a questões de cunho burocrático. Seja qual for a natureza da modalidade, todo material deve ser analisado antes de ser incorporado ao acervo evitando-se dispersão da coleção e a consequente insatisfação dos usuários.

As atividades relativas à aquisição por compra são bastante complexas, como podemos observar no relato abaixo:

\begin{abstract}
À aquisição caberá o trabalho minucioso de identificação, localização dos itens e sua posterior obtenção para o acervo, qualquer que seja a maneira de tornar isto possível. E não é uma tarefa assim tão automática, pois, infelizmente para os profissionais, os títulos selecionados não se encontram acenando para eles ao dobrar da esquina, a gritar 'olha eu aqui, olha eu aqui' e quase implorando para serem adquiridos. Muitas vezes, realizar um trabalho de aquisição assemelha-se a procurar uma agulha em palheiro, tantas são as possibilidades e dificuldades existentes. É uma atividade que exige perseverança e atenção a detalhes, de maneira a evitar um descompasso entre o que foi escolhido primeiramente para aquisição e aquilo que chega às mãos do usuário. (ANDRADE, 1996, p.6).
\end{abstract}

Antes da compra, devem ser previamente definidos os recursos financeiros para permitir uma visão concreta do que se pode contar. Andrade (1996) salienta que, na prática, o orçamento previsto para aquisição de materiais nem sempre corresponde aos recursos liberados, ocasionando que nem todas as necessidades consideradas prioritárias serão atendidas. Vale advertir que parte da verba para aquisição de materiais informacionais deve ser reservada para assinaturas de periódicos, compra de multimeios, obras raras, entre outros.

A maior dificuldade enfrentada pelas bibliotecas jurídicas, no processo de aquisição, é a escassez financeira de recursos que leva forçosamente o bibliotecário a determinar o que é é imprescindível e desprezar os documentos não prioritários. A guisa de exemplo, em vez de comprarmos um título específico (tutela antecipada), efetuaremos a aquisição de um genérico (curso completo de processo civil) que aborda tanto o assunto específico quantos outros igualmente importantes.

Outra solução para melhor gerenciar a falta de recursos financeiros é a aquisição compartilhada, que englobam variados suportes de informação desde os tradicionais como periódicos e livros até os eletrônicos como bases de dados. Seja qual for a estratégia ou medida adotada é necessário realizar processos contínuos de avaliação como veremos mais adiante.

\title{
4.4 Avaliação da coleção
}

A avaliação da coleção deve ser sistemática e entendida como um processo empregado para determinar a importância e a adequação do acervo com os objetivos da Biblioteca e da instituição, possibilitando traçar parâmetros quanto à aquisição, à acessibilidade e ao descarte, sendo, portanto, imprescindível ao bibliotecário jurídico ter conhecimento básico sobre a obsolescência na área. 
Ao iniciar-se a avaliação do acervo deve ser verificado:

O que a biblioteca deveria possuir e não possui e o que possui, mas não deveria possuir, tendo em vista fatores de qualidade e adequação da literatura publicada, sua observância, as mudanças de interesses dos usuários, e a necessidade de otimizar o uso de recursos financeiros limitados. (LANCASTER, 1996, p. 20)

Os métodos utilizados para avaliar o acervo são quantitativos (tamanho e crescimento) e qualitativos (julgamento por especialistas, análise do uso real). Após comparação dos resultados, frutos das análises, assegura-se o alcance dos objetivos da avaliação da coleção, como também se cria um melhor suporte para uma melhor qualidade da política de desenvolvimento de coleções.

A avaliação qualitativa por meio do julgamento por especialistas em um assunto pode trazer alguns problemas, conforme destaca Lancaster (1996): o especialista talvez não seja completamente imparcial, como também, não esteja familiarizado com o perfil da comunidade que a biblioteca atende.

Figueiredo (1991) enfatiza que um meio para realizar a avaliação é por meio da análise comparativa do que é comprado versus o uso subsequente. Esta análise favorece o melhoramento da seleção, quer pela identificação dos tipos de material com pouca chance de ser utilizado, quer pela alteração no processo de seleção que acarreta em compra de materiais desnecessários para a clientela.

$\mathrm{Na}$ avaliação do acervo, são sugeridos os seguintes critérios:

a) Distribuição percentual do acervo por área - é realizada por meio da verificação das estatísticas de uso do material que consentirá na determinação das áreas que devem ter a sua coleção inovada (seja em exemplares, títulos, material em português etc.) e quais áreas de pesquisa encontram-se desprovidas de materiais bibliográficos e especiais que necessitam de providências. Em contrapartida, se for confirmada a subutilização dos recursos bibliográficos em alguma área, a Biblioteca deverá averiguar a causa do problema, podendo ser a falta de qualidade do material existente, desatualização, falha de interesse, desconhecimento da existência da obra etc.

b) Sugestões dos clientes - é um parâmetro seguro para se avaliarem as coleções e, portanto, por meio delas poder-se-á: verificar se a coleção satisfaz os usuários; determinar os tipos e níveis de necessidade em relação às coleções e às mudanças de interesse por parte da clientela.

c) Comparação das coleções com listas, catálogos e bibliografias recomendadas - o emprego deste método incide na comparação do acervo com listas, bibliografias recomendadas e/ou adotadas, para examinar os itens não existentes na biblioteca e quais devem ser adquiridos. Caso os documentos não sejam considerados relevantes nesta fase, procede-se com o seu desbaste.

\subsection{Desbastamento de material bibliográfico e especial}

Desbastamento é o processo pelo qual se exclui do acervo ativo, títulos e/ou exemplares, partes de coleções, quer para remanejamento, descarte ou conservação \begin{tabular}{|l|l|l|l|l|l|}
\hline (C) RDBCI: Rev. Digit.Bibliotecon. Cienc. Inf. & Campinas, SP & v.14 & n.2 & p.262-278 & maio/ago. 2016 \\
\hline
\end{tabular} 
(restauração). É um processo contínuo e sistemático para conservar a qualidade da coleção, ocorrendo sempre devido à necessidade de um processo constante de avaliação da coleção e deve ser feito de acordo com as necessidades da Biblioteca e com o julgamento da Comissão de Biblioteca num prazo que varia entre 03 (três) a 05 (cinco) anos. $\mathrm{O}$ desbastamento não se refere apenas a um simples expurgo de materiais, apesar de englobá-lo no descarte.

\subsubsection{Descarte}

É o processo pelo qual após ser avaliado criteriosamente, o material desatualizado ou inadequado é retirado ou não incluído na coleção ativa. Não tem fundamento guardar material que não corresponda mais aos interesses dos usuários, além de possibilitar a economia de espaço, maior facilidade de acesso ao acervo e mais eficiência no atendimento ao usuário.

Dentre todas as atividades inerentes ao desbastamento, a que exige maior cuidado e segurança, por parte do bibliotecário é o descarte, conforme Vergueiro (1989, p.75) enfatiza bem essa dificuldade.

Afinal - pergunta-se o bibliotecário -, quando se descartar? E para quê? São perguntas que, deve-se reconhecer, constituem reais dilemas para profissionais que tiveram toda uma educação (não apenas a superior) para conservar os materiais informacionais, sob sua responsabilidade, da melhor forma possível, a fim de que esses mesmos materiais pudessem vir a ser utilizados pela coletividade - ou, ao menos, conservados para uma geração futura.

No tocante à informação jurídica, o descarte é indispensável em função de sua abundante produção, começando pela propagação das alterações na legislação, em todos os níveis governamentais (federal, estadual e municipal), estendendo-se pela jurisprudência e pela doutrina.

Para uma maior eficácia desta atividade, é recomendado que se apliquem os mesmos critérios usados no processo de seleção, no momento da apreciação para exclusão dos materiais informacionais pela comissão responsável, pois da mesma forma como seleciona os materiais que devem incorporar ao acervo, também é imprescindível que sejam selecionados os propensos à retirada definitiva.

\section{CONSIDERAÇÕES FINAIS}

Ao longo dos últimos anos, a gestão da qualidade está cada vez mais presente no âmbito das bibliotecas, com o propósito de transformá-las em organizações agregadoras de valor. Para isso, faz-se necessário um bom gerenciamento de seus processos administrativos. Assim, a contínua busca pela melhoria ocorre mediante uma ação sistematizada dos procedimentos por bibliotecários como vistas a identificar possibilidade de melhorias e soluções para a sua organização visando a excelência em seus serviços. Somente com a busca de oportunidade de aprimoramento constante é que se alcança o sucesso e o atingimento dos objetivos propostos. Essa permanente melhoria nos processos fará os usuários distinguirem o valor agregado nos serviços recebidos. 
Constatamos que, diante da rapidez com que se modifica a informação jurídica, é indispensável ao bibliotecário jurídico manter-se atualizado, na busca pelo contínuo acompanhamento das mais recentes alterações da legislação, evitando-se assim a aquisição de publicações ultrapassadas, bem como o fornecimento de informações em desacordo com a legislação em vigor. Seu papel é fundamental não só do ponto de vista da satisfação do usuário como também para cumprir a sua responsabilidade social enquanto mediador de informação.

Com base nas reflexões propostas, pode-se confirmar que o papel da biblioteca jurídica é difundir a informação jurídica principalmente no âmbito das instituições das quais fazem parte, com o intuito de apoiar as decisões nos processos judiciais em curso. Destarte, auxilia os juristas na aplicação da justiça, levando-lhes o Direito em seu estado bruto para que possa ser lapidado por meio das regras de interpretação, achando-se ao final a norma a ser aplicada na solução do caso, contribuindo para pacificação da sociedade. Para tal, é preciso ter-se executado perfeitamente cada fase do desenvolvimento de coleções, para que a coleção espelhe e represente os assuntos relevantes à demanda. A quantidade de títulos para cada área jurídica deve permanecer proporcional aos interesses da instituição mantenedora e da comunidade. Considerando o longo trajeto a ser percorrido, é recomendado elaborar uma política de desenvolvimento da coleção que conglomere os objetivos da instituição mantenedora, com a finalidade de subsidiar a tomada de decisão no processo de seleção, tendo em vista todos os fatores relevantes aos interesses da comunidade, como também avaliar a coleção periodicamente para preservar a qualidade e a integridade física do acervo. A qualidade na política de desenvolvimento de coleções está condicionada à flexibilidade para alterar ou ajustar sempre que for constatado a não satisfação de seus usuários, buscando adequá-la às atuais necessidades informacionais.

Atendendo-se a estes critérios e considerando a importância de uma gestão que vise a aplicação dos preceitos da Qualidade é que as bibliotecas jurídicas poderão cumprir seu verdadeiro papel: a excelência na oferta de informações jurídicas para a melhoria da sociedade como um todo.

\section{REFERÊNCIAS}

ANDRADE, Diva; VERGUEIRO, Valdomiro de Castro Santos. Aquisição de materiais de informação. Brasília: Briquet de Lemos, 1996.

ASSOCIAÇÃO BRASILEIRA DE NORMAS TÉCNICAS. Sistemas de gestão da qualidade - fundamentos e vocabulário: NBR ISO 9000. Rio de Janeiro, 2000.

ASHWORTH, Wilfrid. Manual de bibliotecas especializadas e serviços informatizados. 2. ed. Lisboa: Fundação Calouste GulbenKian, 1981.

CAMPOS, Maria Luiza de Almeida. As cinco leis da biblioteconomia e o exercício profissional. Disponível em: <http://bibliodata.ibict.br/geral/docs/260504.pdf.>. Acesso em: 24 jan. 2016. 
CAPURRO, Rafael; HJORLAND, Birger. O conceito de informação. Perspectivas em Ciência da Informação, Belo Horizonte, v.12, n.1, p.148-207, jan./abr. 2007. Disponível em: $<$ http://www.scielo.br/scielo.php?script=sci_arttext\&pid=S14139362007000100012\&lng=en\&tlng=pt. 10.1590/S1413-99362007000100012>. Acesso em: 23 jan. 2016.

CRONIN JR. John Joseph., TAYLOR, Steven Alexander. Measuring service quality: a reexamination and extension, Journal of Marketing, v.56, p. 55-68, 1992. Disponível em: <http://www.jstor.org/stable/1252296?seq=1\#page_scan_tab_contents>. Acesso em: 21 jan. 2016 .

CROSBY, Philip. Qualidade é investimento. Rio de Janeiro: José Olympio, 1984.

DEMING, William. Edwards. Qualidade: a revolução na administração. Rio de Janeiro: Marques, 1990.

FEIGENBAUM, Armand Vallin. Controle de qualidade total. São Paulo: Makron Books, 1994.

FIGUEIREDO, Nice Menezes de. Metodologias para a promoção do uso da informação: técnicas aplicadas particularmente em bibliotecas universitárias e especializadas. São Paulo: Nobel, 1991.

FIGUEIREDO, Nice Menezes de. Paradignas modernos da Ciência da Informação: em usuários, coleções, referências \& informação. São Paulo: Polis,1999.

FREITAS, André. Luís Pollicani. A qualidade de serviços no contexto da competitividade. Revista Produção on Line, Florianópolis, v. 5, n. 1, p. 1-24, mar. 2005. Disponível em: https://producaoonline.org.br/rpo/article/view/321/418. Acesso em 21 jan. 2016.

GUINCHAT, Claire; MENOU, Michel. Introdução às ciências e técnicas da informação e documentação. Brasília: IBICT, 1994.

JURAN, Joseph. Moses. Controle de qualidade: conceitos, políticas e filosofia da qualidade. São Paulo: McGraw-Hill, 1992.

LE COADIC, Yves-François. A ciência da informação. Brasília: Briquet de Lemos, 1996.

LANCASTER, Frederick. Wilfrid. Avaliação de serviços de bibliotecas. Brasília: Briquet de Lemos, 1996.

MACHADO, Maria Teresa Ferlini. Relacionamento biblioteca/usuário: fator relevante no processo de disseminação da informação jurídica. In: CONGRESSO BRASILEIRO DE BIBLIOTECONOMIA E DOCUMENTAÇÃO, 19., 2000, Porto Alegre. Anais... Porto Alegre: PUCRS, 2000. 1 CD.

MACIEL, Alba Costa; MENDONÇA, Marília Alvarenga Rocha. Bibliotecas como organizações. Rio de Janeiro: Interciência, 2000. 
MIRANDA, Ana Cláudia Carvalho de. A política de desenvolvimento de coleções no âmbito da informação jurídica. In: PASSOS, E. (Org.). Informação jurídica: teoria e prática. Brasília: Thesaurus, 2004.

MIRANDA, Ana Cláudia Carvalho de; D’AMORE, Ticiano Maciel; PINTO, Virginia Bentes. Gestão documental da informação jurídica. Perspectivas em Ciência da Informação, Belo Horizonte, v.18, n.3, p.96-110, jul./set. 2013. Disponível em: < http://www.scielo.br/pdf/pci/v18n3/07.pdf>. Acesso em: 22 jan. 2016.

MULLER, Susana. Pinheiro Machado. A Ciência, o Sistema de Comunicação Científica e a Literatura Científica. In: CAMPELO, Bernadete Santos (Org.). Fontes de informação para pesquisadores e profissionais. Belo Horizonte: UFMG, 2000.

PASSOS, Edilenice. Bibliotecário jurídico: seu perfil, seu papel. Disponível em: <http://www.infolegis.com.br/wa_files/perfilbibjuridico.pdf> . Acesso em 26 jan. 2016.

PASSOS, Edilenice. O controle da informação jurídica no Brasil: a contribuição do Senado Federal. Ciência da informação, Brasília, v.23, n.3, p. 363-368, set./dez. 1994.

PASSOS, Edilenice; BARROS, Lucivaldo. Vasconcelos. Fontes de informação para pesquisa em direito. Brasília, DF: Briquet de Lemos, 2009.

PINTO, Virgínia Bentes. Informação: a chave para a qualidade total. Ciência da Informação, Brasília, v. 22, n. 2, p. 133-137, maio/ago. 1993. Disponível em: <file:///D:/Documents\%20and\%20Settings/f156991/Meus\%20documentos/Downloads/11823476-1-PB\%20(1).pdf> . Acesso em 21 jan. 2016.

SILVA, Armando Malheiro da; RIBEIRO, Fernanda. Das "Ciências" Documentais à ciência da informação: ensaio epistemológico para um novo modelo curricular". Porto: Edições Afrontamento, 2002.

VALLS, Valéria Martins; VERGUEIRO, Valdomiro de Castro Santos. A gestão da qualidade em serviços de informação no Brasil: uma nova revisão de literatura, de 1997 a 2006. Perspectivas em Ciência da Informação, Belo Horizonte, v.11, n.1, p.118-137, jan./abr. 2006. Disponível em: <http://www.scielo.br/pdf/\%0D/pci/v11n1/v11n1a10.pdf>. Acesso em: 22 jan. 2016.

VERGUEIRO, Valdomiro de Castro Santos. Desenvolvimento de coleções. São Paulo: Polis, 1989. (Coleção Palavra-chave, 1).

VERGUEIRO, Valdomiro de Castro Santos. Seleção de materiais de informação. Brasília: Briquet de Lemos, 1995.

VERGUEIRO, Valdomiro de Castro Santos. 2.ed. Brasília: Briquet de Lemos, 1997. 

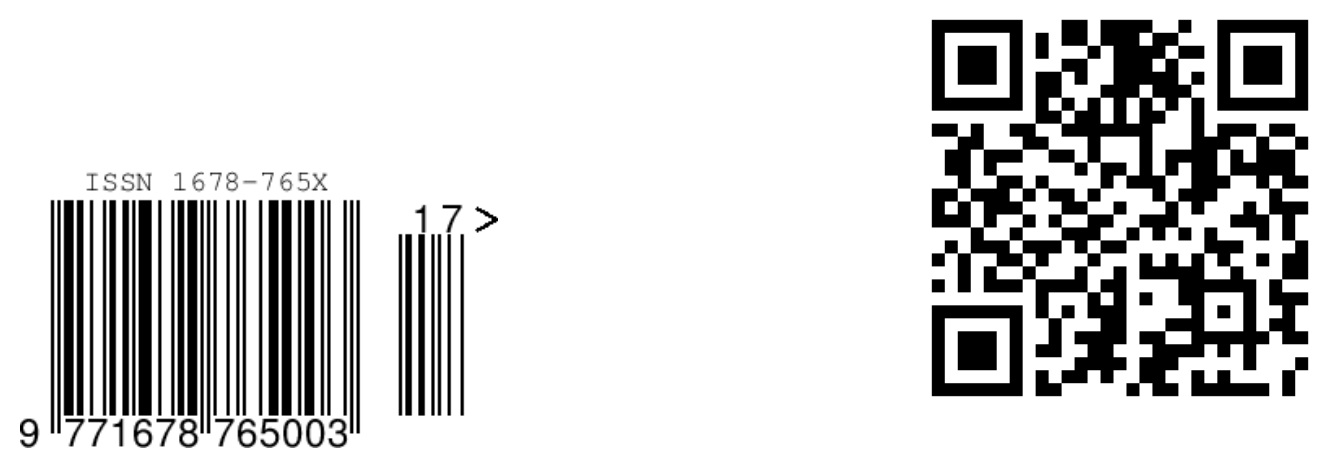